\title{
Loudness of complex sounds as a function of the standard stimulus and the number of components
}

Florentine, Mary; Buus, Søren; Bonding, Per

Published in:

Acoustical Society of America. Journal

Link to article, DOI:

10.1121/1.382062

Publication date:

1978

Document Version

Publisher's PDF, also known as Version of record

Link back to DTU Orbit

Citation (APA):

Florentine, M., Buus, S., \& Bonding, P. (1978). Loudness of complex sounds as a function of the standard stimulus and the number of components. Acoustical Society of America. Journal, 64(4), 1036-1040.

https://doi.org/10.1121/1.382062

\section{General rights}

Copyright and moral rights for the publications made accessible in the public portal are retained by the authors and/or other copyright owners and it is a condition of accessing publications that users recognise and abide by the legal requirements associated with these rights.

- Users may download and print one copy of any publication from the public portal for the purpose of private study or research.

- You may not further distribute the material or use it for any profit-making activity or commercial gain

- You may freely distribute the URL identifying the publication in the public portal 


\title{
Loudness of complex sounds as a function of the standard stimulus and the number of components
}

\author{
Mary Florentine ${ }^{\text {a) }}$ \\ ENT Department, Gentofte University Hospital, 2900 Hellerup, Denmark \\ and Acoustics Laboratory. Technical University of Denmark, 2800 Lyngby, Denmark
}

Søren Buus ${ }^{\text {b) }}$

Acoustics Laboratory, Technical University of Denmark, 2800 Lyngby, Denmark

\section{Per Bonding}

ENT Department, Gentofte University Hospital, 2900 Hellerup, Denmark (Received 15 June 1977; revised 10 April 1978)

\begin{abstract}
The purpose of this study was twofold: to determine if the measured loudness level of a signal depends on the standard stimulus used and to measure loudness as a function of the number of components in a wideband signal. The stimuli were a pure tone, tone complexes with frequency separations of 231 and 1592 $\mathrm{Hz}$, and noise bands with widths of 220 and $1592 \mathrm{~Hz}$. The center frequency was $1 \mathrm{kHz}$ and the loudness level was approximately 65 phons. Loudness matches between all combinations of stimuli showed that the measured loudness of the sounds did not depend on the standard stimulus used and the measured loudness level of a wide-band sound increased as a function of the number of components. Individual observers were consistent in their loudness estimations; the greatest source of variability was among subjects. Additional measurements indicated that the rate at which loudness increased beyond the critical band appéared to be greater for noise bands than for two-tone complexes.
\end{abstract}

PACS numbers: 43.66. Cb

\section{INTRODUCTION}

Zwicker and Feldtkeller (1955) showed that if the overall intensity of a noise band is held constant and bandwidth is increased, there is little or no change in loudness until the critical bandwidth is reached, after which loudness increases. The rate at which loudness increases with bandwidth is most rapid at moderate intensities (Scharf, 1959a; Zwicker and Feldtkeller, 1955; Zwicker, Flottorp, and Stevens, 1957). From 1955 to the present, many experiments have examined loudnesis summation in order to measure the critical band. (For a review, see Scharf, 1970.) Although all these experiments are in reasonable agreement about the width of the critical band at moderate intensities, they disagree about the rate at which loudness increases with bandwidth or frequency separation beyond the critical band. For example, some experiments reveal a slope of 3-4 dB/oct of frequency separation beyond the critical band for normal subjects (Niese, 1960; Port, 1963; Zwicker and Feldtkeller, 1955; Zwicker, Flottorp, and Stevens, 1957), while other experiments reveal slopes of 5-6 dB/oct at comparable intensities (Bonding, 1976; Florentine, 1977). The reason for this difference in obtained slope beyond the critical bandwidth is unclear.

One difference among experiments is the type of stimulus used to measure loudness summation. The most frequently chosen standard stimuli are pure tones,

\footnotetext{
a) Current address: Research Laboratory of Electronics, Massachusetts Institute of Technology, Cambridge, MA 02139.

b) Current address: Auditory Perception Laboratory, Fsychology Department, Northeastern University, Boston, MA 02115.
}

tone complexes, and narrow-band noise. These stimuli have been compared in loudness to tone complexes or noise bands of various widths. The purpose of this paper is twofold: to determine if the rate at which loudness increases beyond the critical band is dependent upon the combination of stimuli used to measure loudness summation and to measure loudness as a function of the number of components in a wide-band signal.

\section{EXPERMENT 1: LOUDNESS SUMMATION AS A FUNCTION OF STIMULUS COMBINATIONS}

\section{A. Method}

\section{Stimuli}

The loudness of five sounds was investigated: a 1 $\mathrm{kHz}$ pure tone, two-tone complexes with frequency separations of 231 and $1592 \mathrm{~Hz}$, and bands of white noise 220 and $1592 \mathrm{~Hz}$ wide. All stimuli were centered geometrically at $1 \mathrm{kHz}$. Limiting frequencies of the twotone complexes and the noise bands are given at the top of Fig. 1. The cutoff frequencies for the noise bands were the points at which the filter output was $3 \mathrm{~dB}$ lower than the maximum output. All stimuli were $1 \mathrm{~s}$ in duration with a rise-fall time of $35 \mathrm{~ms}$. The fixed stimulus alternated with the adjusted stimulus; interstimulus interval was $1 \mathrm{~s}$. The components of the two-tone complexes were set at equal intensity. Preliminary loudness matches showed that for each subject all components were approximately equally loud when equally intense.

\section{Apparatus}

Pure tones were generated by four oscillators (Hewlett-Packard $200 \mathrm{CD}$ ), the $\frac{1}{3}$-oct noise band was generated by passing the output from a white-noise genera- 
tor (Brüel \& Kjaer 1405) through a $\frac{1}{3}$-oct filter (Briel \& Kjaer 1612), and a $1600-\mathrm{Hz}$ noise band was played via a tape recorder (Telefunken M1OA). The $1600-\mathrm{Hz}$ notse band was produced by tape recording (Telefunken M10A) the output of a white-noise generator (Brüel \& KJaer 1405), after filtering by a Krohn-Hite varlable-band filter (3750). Filters attenuated about $24 \mathrm{~dB} /$ oct beyond the half-power points.

Depending upon the experimental condition, a pure tone, two-tone complexes, or noise bands were sent to one or both channels by means of routing switches. After amplification, the continuous signals were gated, attenuated, and then mixed. Both channels were identical except for a sone potentiometer with a $60-\mathrm{dB}$ range in the variable channel. The same Lestron timer which triggered the gates also triggered a shaper positioned after the mixer. This arrangement assured that both signals had identical shape. Next, the signals were attenuated and led to a TDH-39 earphone mounted in a MX-41/AR ear cushion. The stimuli were measured and monitored by an electronic counter (Hewlett-Packard 5223L), an oscilloscope (Tektronix 5103N), and a voltmeter (Brüel \& Kjaer 2603) which measured the rms voltages.

\section{Procedure}

In accordance with a matrix design, each of the five signals was matched in loudness to itself and to each of the other aignals. The 25 matches were run in random order, with a different random order for each subject. Subjects were instructed to pay attention only to the total loudness of the signals. First, the subject matched the. other four signals in loudness to the $\frac{1}{3}$-oct noise band set to $65 \mathrm{~dB}$ SPL. Then each signal was matched in loudness to itself and to each of the other signals. For these matches each standard stimulus was set to the intensity obtained in the first four matches in order to keep the loudness constant. Matches were made monaurally by the method of adjustment. The subjects were instructed to bracket the standard, 1.e., to set the adjusted stimulus alternately louder and soiter than the fixed stimulus, reducing the difference until they perceived equal loudness. After each judgment the experlmenter changed the attenuation in the variable channel in order to prevent position cues on the subject's intensity control knob. Four judgments were made for each stimulus pair. The comparison stimulus was adjusted twice and the standard stimulus was adjusted twice. If the difference between two judgments of Identical stimulus configuration was greater than $3 \mathrm{~dB}$, the judgment was repeated until two judgments with a difference less than $3 \mathrm{~dB}$ were obtained. For approximately $95 \%$ of the matches no extra judgments were required. In approxdmately $5 \%$ of the matches one extra judgment was required; only a few matches required two or more extra judgments. Both the comparison stimulus and the standard stimulus were varied in order to cancel the tendency to set the adjusted stimulus to a higher intensity relative to the fixed atimulus. (See Scharf, 1961.) No time limit was imposed, and the subject usually listened to a palr approximately 20 times before reporting a match.

\section{Subjects}

Ten subjects, six males and four females, were tested. Half of the subjects had previous experience making equal-loudness judgments and the other half had no previous experience except for three practice matches before the onset of data collection. Ages ranged from 20 to 36 jears. Some subjects were paid for their services. All subjects had normal otoscopy and history and their thresholds were within $10 \mathrm{~dB}$ of ISO standard.

\section{B. Results and discussion}

Results for all 25 matches by all ten subjects are summarized in Fig. 1. The level differences needed to obtain equal loudness between the standard stimulus and the comparison stimulus are shown for all combinations of the five stimuli. The horizontal lines indicate the mean values, the white bars represent the interquartile ranges and the black bars represent the total ranges.

An analysis of the means and the covariance was performed on linear combinations of the data. The results of the $X-Y$ match and the $Y \rightarrow X$ match were summed for each individual observer. The mean of these linear combinations was not significantly $(p<0.05)$ different from zero for any combination of two signals. This showed that the results for each observer were symmetrical. In other words, it did not matter which signal was the standard stimulus and which signal was the comparison stimulus.

Furthermore, a two-way analysis of variance revealed that observers show transitivity among all loudness matches. For each observer the sum of the level differences needed to obtain equal-loudness among any three signals approximates zero. Transitivity was confirmed by the fact that the variability among subjects, obtained by pooling data for an $X-Y$ match for all subjects, was aignificantly $(p<0.05)$ greater than the variability within subjects, obtained by pooling the results of the matches over different standard stimuli from one subject.

For all standard stimuli measured, loudness for the wide-band noise was greater than for the wide-band twotone complex. This difference was also found when filters with slopes of approximately $200 \mathrm{~dB} /$ oct were used. On the average, subjects required the wide-band twotone complex to be 10-11 $\mathrm{dB}$ more intense than the wideband noise to obtain equal loudness. This difference was statistically Independent of which standard stimulus was used.

The finding that the measured loudness of a wide-band noise was greater than the measured loudness of a twotone complex appears to be in conflict with an earlter study by Scharf (1959b). He showed that the loudness of tone complexes with widths of 1600 and $3400 \mathrm{~Hz}$ at a center frequency of $1500 \mathrm{~Hz}$ did not depend on the number of components. The reason for this difference is unclear.

The presence of symmetry and trangitivity, in the present data, indicate very consistent and orderly results that are not an artifact of the stimuli and method 


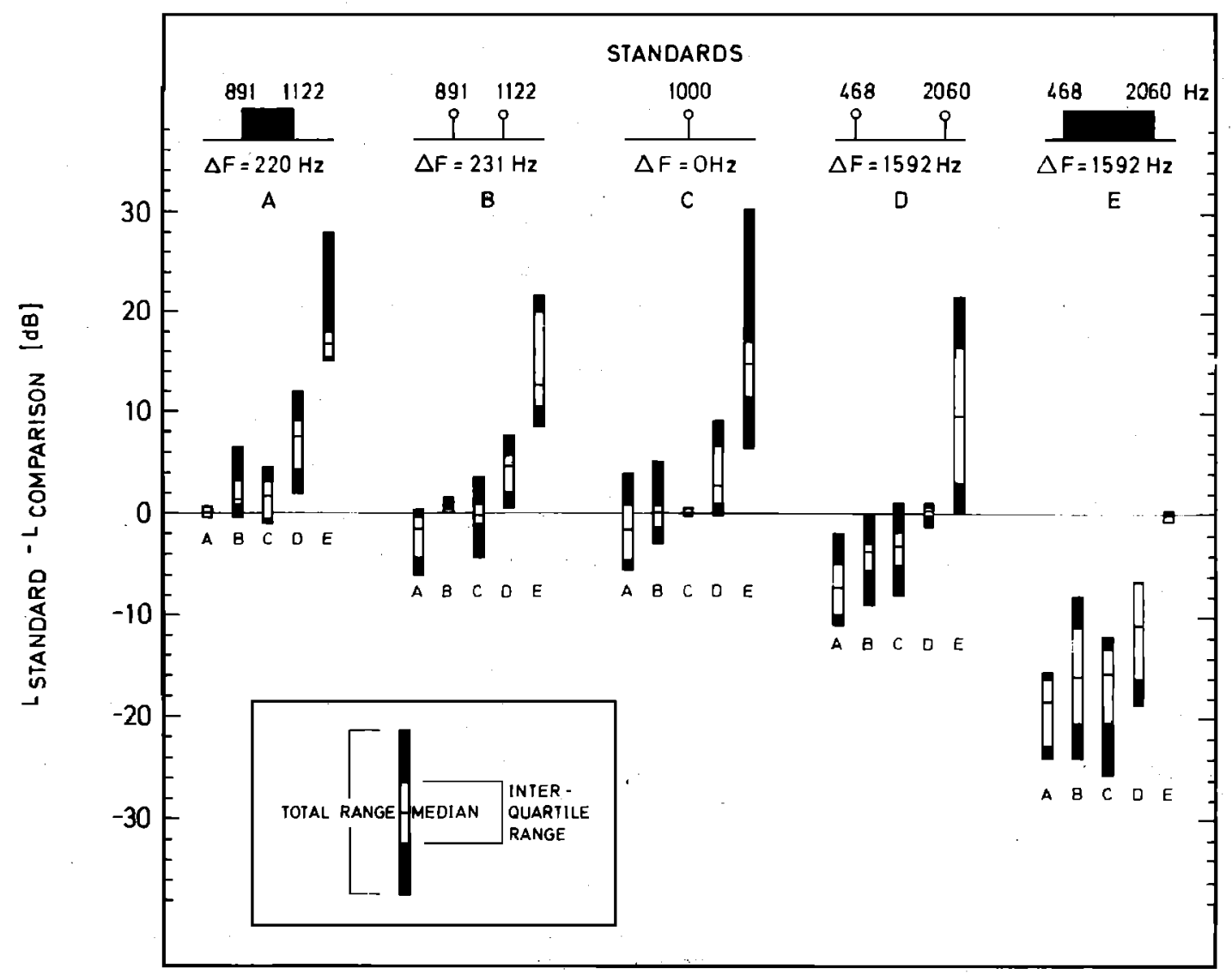

COMPARISONS : $A=\frac{}{\Delta F=220 \mathrm{~Hz}} \quad B=\frac{9}{\Delta F=231 \mathrm{~Hz}} \quad \mathrm{C}=\frac{9}{\Delta \mathrm{F}=\mathrm{OHz}} \quad \mathrm{D}=\frac{0}{\Delta \mathrm{F}=1592} \quad \mathrm{E}=\frac{\mathrm{L}}{\Delta \mathrm{F}=1592 \mathrm{~Hz}}$

FIG. 1. Level differences needed to obtain equal loudness between the standard stimulus and each of the comparison stimuli for the five standard stimuli. Each bar represents a total of 40 judgments by ten subjects. The horizontal lines, white bars, and black bars represent the mediaus, interquartile ranges, and total ranges, respectively.

used in this experiment. Furthermore, we have replicated some of the results of the present experiment with different subjects in three different laboratories using two different psychophysical procedures.

\section{Variability}

Correlations between the loudness estimations of the signals for each subject revealed that subjects were consistent in their judgments of all the stimuli. In other words, if a subject needed a large level difference between two signals to obtain equal loudness when one standard stimulus was used, he also needed a large difference when another standard stimulus was used. When a signal was matched in loudness to itself, variability was approximately the same for all five signals. More variability was obtained when two different signals were matched. When the wide-band noise was matched in loudness to any of the four other sounds significantly $(p<0.05)$ greater variance was obtained than when matching any combination of the other four signals. The fact that variability among subjects was significantly greater $(p<0.05)$ than that within subjects shows that the individual subjects needed different level differences to obtain equal loudness.

\section{EXPERIMENT 2: LOUDNESS SUMMATION AS A FUNCTION OF THE NUMBER OF COMPONENTS}

Experiment 1 suggested that the measured loudness of a wide-band sound may increase as a function of the number of components. The purpose of experiment 2 was to measure the loudness of white noise and of multitone complexes composed of two, three, and four tones.

\section{A. Method}

Five observers were used, four of whom participated in experiment 1. The components of the test stimuli were evenly spaced in frequency around a geometric mean of $1 \mathrm{kHz}$ and set to equal intensity. Each comparison stimulus was matched in loudness to a $220-\mathrm{Hz}$ noise band by the method of adjustment as described in experiment 1 .

\section{B. Results and discussion}

The individual data from the five observers are shown in Fig. 2. For all subjects the measured loudness increases as a function of the number of components. There are two possible reasons why Scharf (1959b) found 


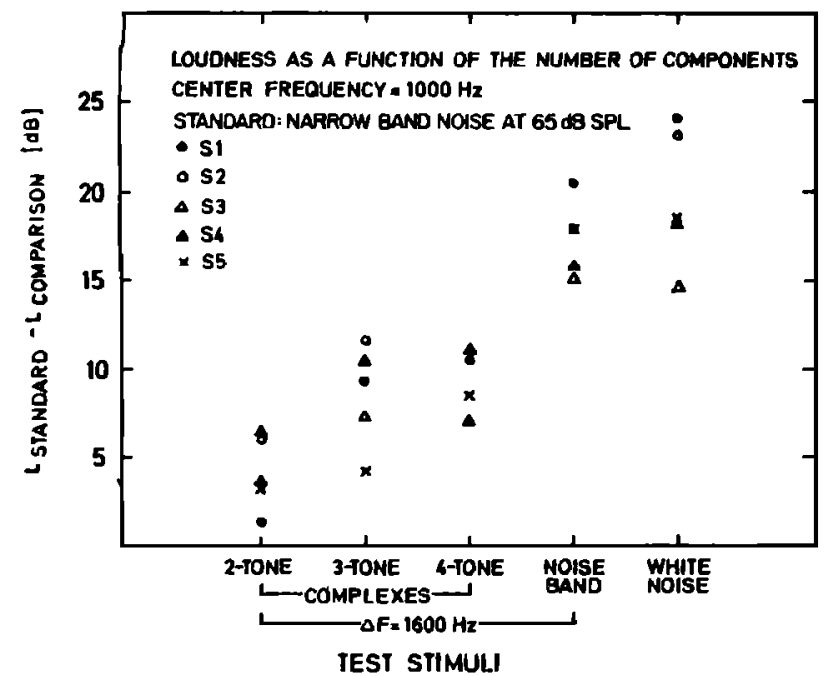

FIG. 2. Level difference needed to obtain equal loudness as a function of the number of components for five aubjects. Each point represents an equal loudness match by the method of adjustment.

no loudness summation as a function of the number of components and we did. The first concerns the treatment of the data. Loudness matches by different observers have generally been pooled. Furthermore, sometimes the same subjects have not served under all experimental conditions. Since the variability among subjects is larger than the variability within subjects, the loudness difference among stimuli could be obscured. A second reason is that Scharf did not test his subjects at $65 \mathrm{~dB}$ SPL, where the maximum loudness summation occurs. Since the total effect of loudness summation was small and variability was large, the difference in loudness summation could not be seen.

It is interesting to note a similarity here between the measured loudness and the acoustic reflex: Threshold of the acoustlc reflex also depends on the number of components in a wide-band sound (Popelka, Karlovich, and Wiley, 1974).

\section{EXPERIMENT 3: LOUDNESS SUMMATION AS A FUNCTION OF BANDWIDTH FOR TWO-TONE COMPLEXES AND NOISE BANDS}

Experiments 1 and 2 suggested that the loudness of a $1592-\mathrm{Hz}$ wide-band signal increases as a function of the number of components. The purpose of experiment 3 was to examine if the rate at which loudness increases beyond the critical band is greater for noise bands than for the two-tone complexes.

\section{A. Method.}

Loudness summation as a function of bandwidth was measured for both noise bands and two-tone complexes. The standard stimulus had a frequency separation of $200 \mathrm{~Hz}$ and was set to $65 \mathrm{~dB}$ SPL. For the nolse bands, a noise band was used as the standard stimulus, and for the two-tone complexes, a two-tone complex was used as standard. The components of the two-tone complex were chosen to assure that they were not har- monic. The method of maximum likelihood, an adaptive forced-choice procedure (Lyregaard and Pedersen, 1971), was used to set the signals equal in loudness. Each match was based on approximately 25 responses. (For further detalls, see Florentine, 1977.)

\section{B. Results and discussion}

Individual data from two observers are shown in Fig. 3. Each point represents the median of three equalloudness matches. Subjects reported that they perceived one sound image and that they tried to base their judgments on the total loudness. Results from both subjects show that loudness summates more rapidly for noise bands than for two-tone complexes even at frequency separations close to the critical bandwidth.

\section{SUMMARY}

(1) Loudness summation did not change with the different standard stimull used in experiment 1.

(2) The rate at which loudness increases beyond the critical band appears to be greater for noise bands than for two-tone complexes.

(3) While the overall bandwidth and intensity of a wide-band stimulus is held constant, loudness increases as components are added.

(4) Individual subjects were. consistent in their loudness estimations. Differences among subjects was the greategt source of variability.

(5) The greatest variability was obtained when the 1592-H2 noise band was matched in loudness to another signal, primarily owing to intersubject variábility.

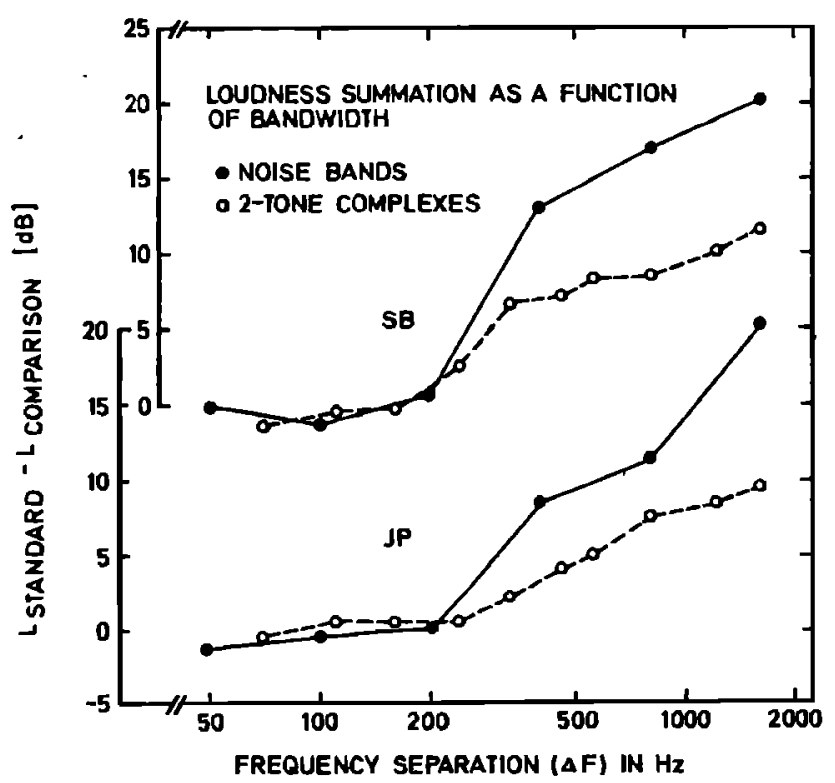

FIG. 3. Level difference needed to obtain equal loudness as a function of frequency geparation $\Delta F$ for two subjects. Each point represents the median of three equal-loudness matches by an adaptive procedure. Each match was based on 25 responses. Filled clrcles and open circles show the results for the nolse-band and tone-complex stimull, respectively. Center frequency was $1 \mathrm{kHz}$ and the comparison was set to $65 \mathrm{~dB}$ SPL. 


\section{ACKNOWLEDGMENTS}

We are grateful to Professor Gerhard Salomon and lecturer $O$. Juhl Pedersen for obtaining funding and providing excellent working conditions, to lecturer Torben Poulsen and civil engineer Claus Elberling for recording the noise band tapes, to Susanne Moller for statistical assistance, and especially to Professor Bertram Scharf and Professor Eberhard Zwicker for reading critically an earlier version of the manuscript. This study was supported by grants from the Research Medical Council and the Tuborg Foundation. Research was carried out while the first author was on leave from the Auditory Perception Laboratory, Northeastern University, Boston, MA 02115.

Bonding, P. (1976). "Critical Bandwidth in Persons with Hearing Loss Due to Salicylate," Proc. 12th Int. Congr. Audiol., Florence, Italy, 142-143.

Florentine, M. (1877). "The Effect of Psychophysical Procedure on Measurements of the Critical Band by Loudness Summation," Rep. No. 20, Acoust. Lab., Tech. Univ. Denmark. Lyregaard, P. E., and Pedersen, O. J. (1971). "Loudness
Level of Impulsive Noise," Rep. No. 6, Acoust. Lab., Tech. Univ. Denmark.

Niese, H. (1980). "Subjectlve Messung der Lautstäke von Bandpassrauschen, Hochfrequenztech. Elektroakust. 68, 202-217.

Popelka, G. R., Karlovich, R. S., and Wiley, T. L. (1974). "Acoustic Reflex and Critical Bandwidth," J. Acoust. Soc. Am. 65, 883-885,

Port, E. (1963). "Über die Lautstärke einzelner kurzer Schallimpulse," Acustica 13, 212-223.

Scharf, B. (1969a). "Critical Bands and the Loudness of Complex Sounds Near Threshold," J. Acoust. Soc. Am. 31, 365380.

Scharf, B. (1968b). "Loudness of Complex Sounds as a Function of the Number of Components," J. Acoust. Soc. Am. 31, 783-785.

Scharf, B. (1961). "Loudness Summation under Masking," J. Acoust. Soc. Am. 33, 503-511.

Scharf, B. (1870). "Critical Bands," in Foundations of Modem Audit ory Theory, edited by J. V. Tobias (Academic, New York), Vol. 1, pp. 157-202.

Zwicker, E., and Feldtkeller, R. (1955). "Über die Lautstärke von gleichrörmigen Geräuschen," Acustica 5, 303-316.

Zwicker, E. , Flottrop, G., and Stevens, S. S. (1987). "Critical Bandwidth in Loudness Summation," J. Acoust. Soc. Am. 28, 548-557. 